\title{
Fibromiyalji Sendromlu Kadın Hastalarda Yaşam Kalitesi ve ilişskili Durumlar
}

\author{
Quality of Life and Associated Conditions in Women with Fibromyalgia Syndrome
}

Didem Sezgin Özcan, Meltem Aras, Belma Füsun Köseoğlu, Şeyma Șentürk Güven

Ankara Fizik Tedavi ve Rehabilitasyon Eğitim ve Araştırma Hastanesi, Ankara, Türkiye

\section{Özet}

Amaç: Fibromiyalji sendromu (FMS), yaygın ağrı ve belirli anatomik bölgelerde hassas noktaların varlığı ile karakterize etyolojisi bilinmeyen romatizmal bir hastalıktır. Yorgunluk, uyku bozukluğu ve psikiyatrik semptomların da eşlik ettiği ağrı nedeniyle hastaların günlük aktiviteleri ve yaşam kalitesi etkilenebilmektedir. Bu çalışmada fibromiyalji sendromlu kadın hastalarda yaşam kalitesi ve yaşam kalitesi ile sosyo-demografik özellikler, depresyon ve uyku bozukluğu arasındaki ilişki incelendi.

Gereç ve Yöntem: Çalısmaya poliklinikte ACR (American College of Rheumatology) kriterlerine (1990) göre FMS tanısı almış 100 kadın hasta alındı. Hastaların sosyo-demografik özellikleri detaylı olarak sorgulandı. Yaşam kalitesini değerlendirmek amacıyla Fibromiyalji Etki Anketi (FEA) kullanıldı. Yaygın ağıı ve uyku bozukluğu şiddetinin değerlendirilmesi amacıyla Vizüel Analog Skala (VAS) (0-10cm) kullanıldı. Depresyon, Beck Depresyon Ölçeği (BDÖ) kullanılarak değerlendirildi.

Bulgular: Fibromiyalji hastalarının yaş ortalaması $42,2 \pm 9,5$ yıl ve ortalama hastalık süresi $32,3 \pm 29,4$ aydı. Hastaların FEA skorlarının ortalaması

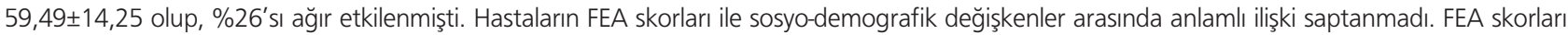
ile ağı VAS, uyku bozukluğu VAS ve BDÖ skorları arasındaki ilişki anlamlı bulundu. Yapılan çoklu regresyon analizinde FEA düzeylerine en fazla katkıda bulunan değişkenin ağrı olduğu, onu sırasıyla uyku bozukluğu ve depresyon skorlarının takip ettiği görüldü.

Sonuç: Depresyon ve uyku bozuklukları, fibromiyaljili hastalarda yüksek oranda görülmektedir ve yaşam kalitesinin bozulmasılya sonuçlanmaktadır. Fibromiyalji tedavisinde nihai amacın yaşam kalitesini yükseltmek olduğu düşünüldüğünde, hastaların depresyon ve uyku bozuklukları açısından klinik değerlendirmesi, tedaviye yön vermesi bakımından önem taşımaktadır. (Türk Osteoporoz Dergisi 2013;19: 42-7) Anahtar kelimeler: Ağrı, depresyon, fibromiyalji sendromu, uyku bozukluğu, yaşam kalitesi

\section{Summary}

Aim: Fibromyalgia syndrome (FMS) is a rheumatic disease of unknown etiology, characterized by widespread pain and tender points at specific anatomical regions. Patients' daily activities and quality of life (QOL) might be affected by severe pain which is accompanied by fatigue, sleep disturbance and psychiatric symptoms. In this study, the QOL of women with fibromyalgia and the relationship between the $\mathrm{QOL}$ and socio-demographic characteristics, depression and sleep disturbance were investigated.

Material and Methods: One hundred women with diagnosis of FMS according to the ACR (American College of Rheumatology) criteria (1990) were included. Socio-demographic characteristics were questioned in detail. Fibromyalgia Impact Questionnaire (FIQ) was used to assess QOL. Visual Analogue Scale (VAS) $(0-10 \mathrm{~cm})$ was used to assess the severity of widespread pain and sleep disturbance. Depression was assessed by using Beck Depression Inventory (BDI).

Results: Mean age was $42.2 \pm 9.5$ years and mean duration of disease was $32.3 \pm 29.4$ months. The mean FIQ total score was $59.49 \pm 14.25$ and $\% 26$ of the patients were severely affected. There was no association between FIQ scores and socio-demographic variables. There were statistically significant relationship between FIQ scores and pain VAS, sleep disturbance VAS and BDI scores. In the multivariate regression analysis, pain was the most contributing variable to FIQ level and it was followed by sleep disturbance and depression scores, respectively.

Conclusion: Depression and sleep disturbances are commonly encountered in patients with fibromyalgia which result in deterioration of QOL. Given that the final purpose of the management of fibromyalgia is to improve the quality of life, clinical evaluation of depression and sleep disturbances should be regarded to guide therapy. (Turkish Journal of Osteoporosis 2013;19: 42-7)

Key words: Depression, fibromyalgia syndrome, pain, quality of life, sleep disturbance

Yazışma Adresi/Address for Correspondence: Dr. Didem Sezgin Özcan, Ankara Fizik Tedavi ve Rehabilitasyon Eğitim ve Araştırma Hastanesi, Ankara, Türkiye Tel.: +90 3123103230 E-posta: sezgindidem@gmail.com Geliș Tarihi/Received: 11.07.2013 Kabul Tarihi/Accepted: 06.08.2013

Türk Osteoporoz Dergisi, Galenos Yayınevi tarafindan basılmıştır. / Turkish Journal of Osteoporosis, published by Galenos Publishing. 


\section{Giriş}

Fibromiyalji sendromu (FMS), yaygın vücut ağrısı ve belirli anatomik bölgelerde hassas noktaların varlığı ile karakterize etyolojisi bilinmeyen bir romatizmal hastalıktır $(1,2)$. Fibromiyalji sendromunda ağrıya yorgunluk, sabah tutukluğu, depresyon, uyku bozukluğu başta olmak üzere çeşitli somatik ve psikolojik semptomlar eşlik etmektedir(2). Fibromiyalji toplumun \%1-2'sini etkiler ve çoğunluğu 40-55 yaş arası kadın hastalar oluşturur $(1,3)$. Yapılan araştırmalar FMS'de nöroendokrin, otonom ve immünolojik mekanizmaların rol oynadığını ve genetik olarak yatkın kişilerde çevresel, fizyolojik ve psikolojik faktörler gibi bazı stresörlerle hastalığın geliştiğini ortaya koymaktadır. Özellikle son yıllardaki çalışmalar santral mekanizmaların etkinliğini desteklemekte ve tedavide yeni açılımlara yol açmaktadır $(1,2,4)$.

Fibromiyalji sendromu, duygu durum bozuklukları ve uyku bozukluklarının sıklıkla ağrıya eşlik etmesi nedeniyle uzun yıllar psikolojik bir hastalık olarak düşünülmüştür. Psikolojik faktörler başta kronik ağrı olmak üzere her türlü ağrının önemli bir bileşenidir ve kısır döngü içinde birbirlerini besleyen bir etkileşim oluştururlar. Daha önce yapılan birçok çalışmada FMS'li hastalarda ömür boyu depresyon ve anksiyete prevalansında normal populasyona göre artış saptanmıştır (5-7).

Yaşam kalitesi, bireylerin, hayat içerisindeki durumlarını, ait oldukları kültürel yapı ve değerler sistemi bağlamında, algılama ve değerlendirme biçimidir (8). Daha önce yapılan çeşitli çalışmalarda FMS'li hastalarda yaşam kalitesinin negatif yönde etkilendiği gösterilmiştir (9-12). Yaygın ağrı, yorgunluk, uyku bozuklukları ve psikiyatrik semptomlar yaşam kalitesindeki bozulmada etkili gözükmektedir. İş gücü kaybı ve yüksek sağlık giderlerine yol açan hastalığın tedavisinde temel hedef ağrının azaltılarak yaşam kalitesinin arttırımasıdır.

Fibromiyalji sendromunda yaşam kalitesine etki eden faktörlerin belirlenmesi hastalığın tedavisine yön verme aşamasında önemli gözükmektedir. Biz de çalışmamızda polikliniğimize başvuran FMS'li kadın hastalarımızda yaşam kalitesini ve yaşam kalitesinin sosyo-demografik özellikler, depresyon, uyku bozukluğu ve ağrı şiddeti ile ilişkisini inceledik

\section{Gereç ve Yöntemler}

Bu çalışma Ocak 2010-Ağustos 2011 tarihleri arasında Ankara Fizik Tedavi ve Rehabilitasyon Eğitim Araştırma Hastanesi polikliniğine başvuran 1990 ACR kriterlerine göre FMS tanısı konan 18-65 yaş arası 100 kadın hasta üzerinde yapıldı. Çalışmaya alınan tüm hastalar çalışma hakkında bilgilendirilip, onamları alındı. Hastalara uygulanan standart değerlendirme formuyla sosyo-demografik özellikler, hastalık süresi, FM'ye eşlik eden semptomlar, ağrı, uyku bozukluğu ve depresyon şiddeti sorgulandı.

\section{Sosyo-demografik Özelliklerin Değerlendirmesi}

Hastaların cinsiyet, yaş, boy, kilo, vücut kitle indeksi (VKi), medeni durum, çocuk sayısı, mesleki durumu, çalışma durumu, eğitim durumu, sigara kullanımı ve gelir düzeyi sorgulandı.

\section{Ağrı ve Uyku Bozukluğu Şiddeti Değerlendirmesi}

VAS (Vizüel Analog Skala) kullanılarak değerlendirildi. Hastaların ağrı ve uyku bozukluğu düzeylerini $10 \mathrm{~cm}$ 'lik çizgi üzerinde işaretlemeleri istendi. Çalışmamızda 0-3 puan hafif, 4-6 orta, 7-10 puan şiddetli olarak değerlendirildi (13).

\section{Depresyon Değerlendirmesi}

Hastalarda depresyon varlığı ve şiddeti Beck Depresyon Ölçeği (BDÖ) kullanılarak değerlendirildi (14). Toplam 21 maddeden oluşan ölçekte her madde 4 cümleden oluşmaktadır. Bu cümleler, nötral durumdan (0 puan), en ağır duruma (3 puan) göre sıralanmıştır. Çalışmamızda anket şeklinde düzenlenen bu ölçekte, hastalardan kendilerine en uygun olan cümleyi seçmeleri istendi. Toplam puan olarak 0-12 minimal, 13-18 hafif, 19-28 orta ve 29-63 ise şiddetli depresyon olarak değerlendirildi (15).

\section{Fonksiyonel Değerlendirme ve Yaşam Kalitesi}

Çalışmamızda FMS'de yaşam kalitesini ve fonksiyonel durumu değerlendirme amacıyla Sarmer ve arkadaşları tarafından Türkçe geçerlilik ve güvenilirliği gösterilmiş olan Fibromiyalji Etki Anketi (FEA) kullanıldı (16). Bu ölçekte fiziksel fonksiyon, kendini iyi hissetme hali, işe gidememe, işte zorlanma, ağrı, yorgunluk, sabah yorgunluğu, tutukluk, anksiyete ve depresyon olmak üzere 10 ayrı özellik ölçülmektedir. Kendini iyi hissetme özelliği hariç, düşük skorlar iyileşmeyi veya hastalıktan daha az etkilenildiğini gösterir. FEA, hasta tarafından doldurulmaktadır ve maksimum skor 100 'dür. Ortalama bir FM hastası 50 puan alırken, ağır etkilenmiş bir hasta genellikle 70 'in üzerinde puan alır (17).

\section{Verilerin Analizi}

Verilerin istatistiksel değerlendirmesi SPSS 20.0 kullanılarak yapıldı. Verilerin normal dağılıma uygunluğu Shapiro-Wilk testiyle araştırıldı. Nicel verilerin ortalaması, ortanca (minimummaksimum) ve ortalama \pm standart sapma olarak gösterildi. Nitel veriler ise sayı (n) ve yüzde (\%) şeklinde ifade edildi.

FEA skorları ile sosyo-demografik veriler arasındaki ilişkinin değerlendirilmesinde Student's T test, Varyans analizi ve lineer regresyon analizi kullanıldı. FEA skorları ile ağrı VAS, uyku bozukluğu VAS ve BDÖ skorları arasındaki ilişki, veriler parametrik varsayımları sağlamadığından Spearman korelasyon analizi ile değerlendirildi. FEA skorları üzerinde birden fazla bağımsız değişkenin toplu etkisinin değerlendirilmesinde çoklu regresyon analizi kullanıldı. Analizler $p<0.05$ ise anlamlı kabul edildi.

\section{Bulgular}

Çalışmaya katılan 20-65 yaş arası 100 kadın hastanın yaş ortalaması 42,2 $\pm 9,5$ yıl, ortalama hastalık süresi ise $32,3 \pm 29,3$ aydı. Hastaların diğer sosyo-demografik özellikleri Tablo 1'de

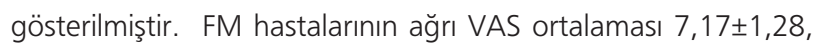
FEA skor ortalaması ise 59,49 $\pm 14,25$ idi. Fibromiyalji hastalarının klinik değerlendirme skalaları ve şiddete göre alt grupları Tablo 2'de gösterilmiştir. 
Fibromiyalji hastalarının sosyo-demografik özellikleri ve FEA skorları ile değerlendirilen yaşam kaliteleri arasındaki ilişki Tablo 3'te gösterilmiştir. Hastalar medeni durum, eğitim düzeyi, gelir düzeyi, çalışma durumu, sigara kullanım durumuna göre kategorize edildiğinde gruplar arasında FEA skorları açısından anlamlı fark olmadığı saptandı ( $p>0,05)$. Ayrıca yapılan regresyon analizinde yaş, çocuk sayısı ve VKi ile FEA skorları arasındaki ilişki anlamlı bulunmadı $(p>0,05)$.

Fibromiyalji hastalarında yaşam kalitesi, yaygın ağrı, uyku bozukluğu ve depresyonun birbirleriyle ilişkisi değerlendirildi. FEA skorları ile ağrı VAS, uyku bozukluğu VAS ve BDÖ skorları arasında anlamlı korelasyon saptandı (sırasıyla r:0,622 $p<0,001, r: 0,504 p<0,001, r: 0,653 p<0,001)$. Ayrıca ağrı VAS, uyku bozukluğu VAS ve BDÖ skorlarının kendi aralarında korelasyonları değerlendirildi ve sonuç istatistiksel olarak anlamlı

\section{Tablo 1. Hastaların sosyo-demografik özellikleri}

\begin{tabular}{|c|c|}
\hline & $n=100$ \\
\hline Yaş, Ort $\pm S S$ & $42,2 \pm 9,4$ \\
\hline Boy $(\mathrm{cm})$, Ort $\pm S S$ & $160,7 \pm 6,8$ \\
\hline Kilo (kg), Ort $\pm S S$ & $71,3 \pm 11,7$ \\
\hline VKI $\left(\mathrm{kg} / \mathrm{m}^{2}\right)$, Ort $\pm S S$ & $27,6 \pm 4,7$ \\
\hline Çocuk sayısı, Ortanca (Min-Maks) & $2(0-6)$ \\
\hline
\end{tabular}

Medeni durum $\mathrm{n}(\%)$

\begin{tabular}{|l|l|l|}
\hline & Bekar & $9(9)$ \\
\hline & Evli & $88(88)$ \\
\hline & Dul & $3(3)$ \\
\hline
\end{tabular}

Eğitim düzeyi $n(\%)$

\begin{tabular}{|l|l|l|}
\hline & Okuma yok & $7(7)$ \\
\hline & Ilkokul & $53(53)$ \\
\hline & Ortaokul & $14(14)$ \\
\hline & Lise & $12(12)$ \\
\hline & Üniversite & $14(14)$ \\
\hline
\end{tabular}

Gelir düzeyi $n(\%)$

\begin{tabular}{|l|l|l|}
\hline & Düşük & $44(44)$ \\
\hline & Orta-yüksek & $56(56)$ \\
\hline \multicolumn{2}{|c|}{ Çalışma durumu n(\%) } \\
\hline & Çalışıyor & $24(24)$ \\
\hline & Hiç çalışmamış & $66(66)$ \\
\hline & İşi bırakan & $10(10)$ \\
\hline Sigara kullanma n(\%) & İçmiyor \\
\hline \multicolumn{2}{|l}{} \\
\hline & İçiyor & $26(26)$ \\
\hline \multicolumn{2}{|l|}{ Bırakmış } & $4(4)$ \\
\hline \multicolumn{2}{|l}{} \\
\hline
\end{tabular}

bulundu $(p<0,01)$. Klinik skalalar arasındaki korelasyon analizleri Tablo 4'te gösterilmiştir.

Yapılan çoklu regresyon analizinde ağrı, uyku bozukluğu ve depresyon ile yaşam kalitesi arasındaki ilişkinin istatistiksel olarak anlamlı olduğu ve bu üç değişkenin FEA skorlarına \%58 oranında katkıda bulunduğu saptandı $(F(3,96)=43,802$; $p<0,001)$. Ayrıca aralarında yaşam kalitesini en fazla etkileyen değişkenin ağrı düzeyi olduğu, onu sırasıyla uyku bozukluğu ve depresyon şiddetinin takip ettiği görüldü. (Tablo 5).

\section{Tartışma}

Daha önce yapılmış birçok çalışmada Fibromiyalji sendromlu hastaların yaşam kalitesi, sağlıklı kontrollerle, diğer romatizmal ve non-romatizmal hastalıklarla karşılaştırılmıştır ve FMS'li hastalarda yaşam kalitesinin düşük olduğu ortaya konulmuştur(3,18-20). Bizim çalışmamızda ise amaç fibromiyaljili hastalarda düşük yaşam kalitesine yol açabilecek çeşitli faktörleri değerlendirmek ve yaşam kalitesiyle ilişkisini incelemekti. Uyku bozukluğu, ağrı ve depresyonla birlikte sosyodemografik verilerin de yaşam kalitesi değerlendiriminde göz önünde tutulması çalışmamıza bütünleyici bir özellik kazandırmaktadır.

Fibromiyaljili hastalarda yaşam kalitesini değerlendirmede çeşitli ölçekler kullanılmakta ve bu ölçeklerinin kullanımı, hastaların intiyaçlarının tanımlanması, tedavi etkinliğinin değerlendirilmesi

Tablo 2. Fibromiyalji hastalarının klinik değerlendirme skalaları ve șiddete göre alt grupları

\begin{tabular}{|c|c|c|}
\hline & & $n=100$ \\
\hline FEA (ort $\pm S S$ ) & & $59,49 \pm 14,25$ \\
\hline \multirow[t]{2}{*}{$n(\%)$} & hafif & $74(\% 74)$ \\
\hline & şiddetli & $26(\% 26)$ \\
\hline Ağrı VAS (ortะSS) & & $7,17 \pm 1,28$ \\
\hline \multirow[t]{2}{*}{$n(\%)$} & hafif-orta & $29(\% 29)$ \\
\hline & şiddetli & $71(\% 71)$ \\
\hline $\begin{array}{l}\text { Uyku bozukluğu VAS } \\
\text { (ort } \pm S S \text { ) }\end{array}$ & & $4,72 \pm 2,24$ \\
\hline \multirow[t]{3}{*}{$n(\%)$} & hafif & $34(\% 34)$ \\
\hline & orta & $44(\% 44)$ \\
\hline & şiddetli & $22(\% 22)$ \\
\hline BDÖ (ort $\pm S S$ ) & & $20,25 \pm 10,37$ \\
\hline \multirow[t]{4}{*}{$n(\%)$} & minimal & $26(\% 26)$ \\
\hline & hafif & $27(\% 27)$ \\
\hline & orta & $22(\% 22)$ \\
\hline & şiddetli & $25(\% 25)$ \\
\hline \multicolumn{3}{|c|}{$\begin{array}{l}\text { BDÖ: Beck depresyon ölçeği (0-12:minimal, 13-18: hafif, 19-28: } \\
\text { orta, 29-63: şiddetli) } \\
\text { FEA: Fibromiyalji Etki Anketi (0-70: hafif, 71-100: şiddetli) } \\
\text { VAS: Vizüel analog skala ( 0-3 cm: hafif, 4-6 cm: orta, 7-10 cm: } \\
\text { şiddetli düzeyde) }\end{array}$} \\
\hline
\end{tabular}


ve takip edilmesi açısından önem taşımaktadır. En sık kullanılanları FEA ve SF-36 olup, çeşitli çalışmalarda birlikte kullanımları da mevcuttur. Son yıllarda, kısa olması, uygulama ve skorlama kolaylığı ve sensitivitesi nedeniyle FEA, FM hastalarında en yaygın kullanılan ölçek durumuna gelmiştir $(17,21)$. Pagano ve ark.'nın yaptığı bir çalışmada FEA'nın FM'yi tanımlamada SF-36'dan daha etkili bir ölçüm metodu olduğu ve bu nedenle sadece FM'li popülasyonların değerlendirildiği durumlarda tercih edilebileceği belirtilmiştir (3). Bu nedenle sadece FM'li hasta grubunu incelediğimiz çalışmamızda, hastalarımızda yaşam kalitesini değerlendirmede FEA'nin kullanılması tercih edildi. FEA skorlarına göre hastalarımızın \%74'unun hafif, \%26'sinin ise ağır etkilenmiş fibromiyalji olduğu saptandı.

Sosyo-demografik verilerle yaşam kalitesi ilişkisini değerlendiren fazla çalışma olmamakla birlikte sonuçlar çelişkilidir. Ubago Linares ve ark.'nın yaptığı bir çalışmada, FEA skorları ile cinsiyet, yaşam alanı (kırsal/şehir), evlilik durumu, çalışma durumu, aylık gelir, eğitim seviyesi, yaş ve çocuk sayısı arasındaki ilişki değerlendirilmiş ve fazla çocuk sayısı, yaş artışı ve düşük eğitim seviyesi daha düşük yaşam kalitesi ile ilişkili bulunmuştur (21).
Campos ve ark.'nın yaptığı bir çalışmada ise sosyo-demografik verilerden şehirde yaşama durumunun, daha iyi yaşam kalitesi ile ilişkili olduğu saptanmıştır (11). Bizim çalışmamızda inceledigimiz hiçbir sosyo-demografik veri ile FEA skoru arasında anlamlı ilişki saptanmadı. Çalışmalarda değerlendirilen hasta sayılarının kısıtlı olması sonuçların anlamlı çıkmamasının sebebi olabilir. Sosyodemografik verilerle yaşam kalitesi arasındaki ilişki daha geniş hasta popülasyonlu çalışmalarla değerlendirilmelidir.

Yaygın kas-iskelet sistemi ağrısı FM'nin ana semptomudur. Ağrı şiddetinin değerlendirilmesi, hastalık şiddetinin saptanması ve takibinde önem taşımaktadır. Çeşitli çalışmalarda FM'de ağrı modülasyonunda görevli nörotransmitterlerde düşüklük ve endojen opioid sisteme ait birçok peptidin ağrıyı modüle etmekte yetersiz kaldığı görülmüştür. Çalışmamızda FM'li hastalardaki yaygın ağı VAS ortalaması 7,17 olarak tespit edildi. Bu değerin daha önce yapılmış çalışmalarla uyumlu olduğu görüldü $(6,03-7,63)(11,20)$.

Yaşam kalitesi ile ağrı, uyku bozukluğu ve depresyon arasındaki ilişki çalışmamızda anlamlı bulundu ve bu üç değişkenden yaşam kalitesinde bozulmaya en fazla katkıda bulunan değişkenin

\section{Tablo 3. FEA skorları ve sosyo-demografik özellikler arasındaki ilișki}

\begin{tabular}{|c|c|c|c|c|}
\hline Sosyo-demografik özellikler & $\mathrm{n}$ & $\%$ & FEA (ort $\pm S S)$ & p değeri \\
\hline \multicolumn{5}{|l|}{ Medeni durum n(\%) } \\
\hline Bekar & 12 & 12 & $55,63 \pm 10,2$ & $0,32^{\mathrm{a}}$ \\
\hline Evli & 88 & 88 & $60,01 \pm 14,68$ & \\
\hline \multicolumn{5}{|l|}{ Eğitim düzeyi n(\%) } \\
\hline Okuma yok & 7 & 7 & $62,88 \pm 7,07$ & $0,273^{b}$ \\
\hline ilkokul & 53 & 53 & $60,04 \pm 14,41$ & \\
\hline Ortaokul & 14 & 14 & $57,76 \pm 16$ & \\
\hline Lise & 12 & 12 & $64,63 \pm 14,67$ & \\
\hline Yüksekokul & 14 & 14 & $52,99 \pm 13,16$ & \\
\hline \multicolumn{5}{|l|}{ Gelir düzeyi n(\%) } \\
\hline Düşük & 44 & 44 & $58,36 \pm 13,68$ & $0,487^{a}$ \\
\hline Orta-yüksek & 56 & 56 & $60,36 \pm 14,73$ & \\
\hline \multicolumn{5}{|l|}{ Çalışma durumu n(\%) } \\
\hline Çalışıyor & 24 & 24 & $58,42 \pm 13,6$ & $0,679^{a}$ \\
\hline Çalışmıyor & 76 & 76 & $59,82 \pm 14,52$ & \\
\hline \multicolumn{5}{|l|}{ Sigara kullanma n(\%) } \\
\hline İçmiyor & 74 & 74 & $58,31 \pm 14,28$ & $0,167^{a}$ \\
\hline İciyor & 26 & 26 & $62,81 \pm 13,88$ & \\
\hline Yaş & $42,2^{C}$ & $9,4^{d}$ & $0,09 \mathrm{e}$ & $0,55^{f}$ \\
\hline Çocuk sayısı & 29 & $0-6^{h}$ & $1,522^{e}$ & $0,17^{f}$ \\
\hline VKi $\left(\mathrm{kg} / \mathrm{m}^{2}\right)$ & $27,6^{C}$ & $4,7^{d}$ & $0,168^{e}$ & $0,59^{f}$ \\
\hline \multicolumn{5}{|c|}{$\begin{array}{l}\text { aStudent T Test } b_{\text {Tek yönlü varyans analizi, }}{ }^{C} \text { Ortalama, }{ }_{\text {Standart Sapma, }} e_{\text {Katsayı }} f_{\text {Lineer Regresyon Analizi }} \text { GOrtanca } \\
\text { h Minimum-Maksimum } \\
\text { VKi: Vücut kitle indeksi }\end{array}$} \\
\hline
\end{tabular}


ağrı düzeyi olduğu, onu sırasıyla uyku bozukluğu ve depresyon şiddetinin takip ettiği tespit edildi. Fibromiyalji ile ağrı, uyku, duygu-durum bozukluklarının nedensel ilişkisi ve birbirleriyle ilişkisi çok net olmamakla birlikte tetikleyici nöroendokrin ve genetik faktorlerin olduğu yönünde kanıtlar mevcuttur. Örnek olarak serotoninin ağrı sinyal iletiminde, uyku regülasyonunda ve duygudurum açısından önemli olduğu ve serotonin anormalliklerinin FM ve FM ilişkili uyku ve duygu durum bozukluklarında rol oynayabileceği düşünülmektedir (24).

Depresyon FM'li hastalarda sık görülen psikiyatrik komorbiditelerden biridir ve çeşitli çalışmalarda prevalansı \%20-80 olarak bildirilmiştir (25). Depresif semptomların FM'li hastalar ve sağlıklı kontroller arasında karşılaştırıldığı birçok çalışmada FM hasta grubunda depresif semptomu olanların oranı, kontrol grubuna göre belirgin olarak yüksek bulunmuştur $(12,26)$. FM ve depresyon birlikteliği ile ilgili çeşitli olasılıklar öne sürülmüştür. Bunlar: Depresyonun kronik ağrı ve dizabiliteye sekonder olarak gelişen reaktif bir durum olduğu; FM'nin depresyon eşiğini düşürdüğü ve son olarak da FM ve depresyonun birçok periferal ve santral belirtiler açığa çıkaran aynı affektif spektruma ait hastalıklar olabileceğini görüşleridir (27). Çalışmamızda BDÖ ve FEA skorları arasında anlamlı korelasyon saptanarak, depresif semptom şiddeti artışının yaşam kalitesini negatif yönde etkilediği tespit edildi. Depresyon, ağrı algılaması ve fonksiyonel dizabiliteyi artırarak, enerjiyi düşürerek, boş zaman aktivitelerine ilgiyi, motivasyonu azaltarak ve kişiler arası iletişimi bozarak hastaların yaşam kalitesini etkilemektedir $(12,20)$. Çalışmamızda depresyon ve ağı düzeyi arasındaki ilişki değerlendirildi ve anlamlı bulundu. Literatürde depresyon ve ağrı yoğunluğu arasındaki ilişkiyi inceleyen çalışmalarda çelişkili sonuçlar mevcuttur. Bazı çalışmalarda depresyon ile kronik ağrı arasında ilişki olmadığı bildirilmiş ve ağrı yoğunluğunun depresyonun nedenini açılayamayacağı öne sürülmüştür $(28,29)$. Homan ve ark.'nın yaptığı bir çalışmada ise depresif semptomların şiddeti arttıkça, ağrı yoğunluğu artmış, günlük yaşam aktivitelerindeki performans düşerek yaşam kalitesi negatif yönde etkilenmiştir (12). Birçok çalışma serotonin ve norepinefrinin depresyonda işe karıştığını ayrıca beyin ve medulla anti-ağrı sisteminin bir parçası olduğunu göstermektedir (30).

Fibromiyaljili hastaların çoğu (\%75-90) derinleşmeyen, dinlendirici olmayan uyku bozukluğundan yakınır. Fibromiyaljili hastalarda uykunun en derin fazında, delta dalga uykusunda normalde görülmemesi gereken alfa dalgalarının bulunması, rahatlatmayan uykuya sebep olmaktadır (31). Uyku bozuklukları FM'li hastalarda sık görülse de yaşam kalitesi ile ilişkisini gösteren çalışma sayısı azdır (32). Wagner ve ark.'nın yaptığı bir çalışmada uyku bozukluğu olan hastaların yaşam kalitesi, olmayanlara göre belirgin olarak düşük bulunmuştur (33). Bizim çalışmamızda da uyku bozukluğu VAS ve FEA skorları arasında anlamlı korelasyon saptandı. Çalışmamızda ayrıca FM'li hastalarda depresyon ve uyku bozukluğu şiddeti arasındaki ilişki de değerlendirildi ve aralarındaki ilişki anlamlı bulundu. Uyku bozuklukları, depresyon semptomatolojisinde önemli ve değişmeyen bir yere sahiptir. Uykuya dalmanın gecikmesi, uyuma süresinin uzaması, sabah erken uyanma ve gündüz uykululuk hali gibi şekillerde kendini gösterebilir. Ayrıca uyku bozukluğu, depresyon patogenezine de katkıda bulunmaktadır. Depresyon ve uyku bozukluğu arasındaki yakın ilişki, çalışmamızda bulduğumuz sonuçları destekler niteliktedir. Çalışmamızda ağrı ve uyku bozukluğu arasındaki ilişki de değerlendirildi ve sonuç anlamlı bulundu. FM'li hastalarda yapılan elektroensefalografik çalışmalar, uykunun en sık 4. fazının etkilendiğini ve bunun da direkt olarak kas mikrotravmalarının tamirinde rolü olan GH ve IGF-1'de defisitle sonuçlandığını göstermektedir. Yine bu hastalar yüksek ACTH düzeyleri tarafından indüklenen artmış somatostatin ( $\mathrm{GH}$ inhibitörü) düzeylerine sahiptir. Dolayısıyla hasarlı kas dokusundan santral sinir sistemine olan sensoriyal stimulus iletiminde uzama olmakta ve kas ağrı algısı artmaktadır. Yine bu artmış ağrı da uyku bozukluğuna katkıda bulunabilmekte ve böylece hastanın yorgunluğu ve kas dokusunun yetersiz tamiri devamlı hale gelmektedir $(1,23)$.

Ağrı şikayetine ek olarak depresyon ve uyku bozuklukları, çalışmamızda da gösterildiği gibi, FM'li hastalarda yüksek oranda görülmekte, yaşam kalitelerinin bozulmasına, ağrı şiddet ve algılamasının artmasına yol açmaktadır. Fibromiyalji tedavisinde nihai amacın yaşam kalitesini yükseltmek olduğu düşünüldüğünde, hastaların depresyon ve uyku bozuklukları açısından klinik değerlendirmesi, tedaviye yön vermesi bakımından önem taşımaktadır. Son yapılan çalışmalar da FM tedavisinde farmakolojik tedavi, psikoterapi, eğitim programları, ağrı ve yorgunluk kontrolü, uyku paterni iyileştirilmesi, duygudurum kontrolü ve psikososyal reintegrasyonu içeren multidisipliner yaklaşımı önermektedir (34-36).

Sonuç olarak çalışmamızda FM'li kadın hastalarda yaşam kalitesinin negatif yönde etkilendiği, ağrı düzeyi, depresyon ve uyku bozukluğu ile de ilişkili olduğu tespit edildi. Ayrıca ağrı, depresyon ve uyku bozukluğunun birbirleriyle korelasyonu istatistiksel olarak anlamlı bulundu. Yaşam kalitesi ve sosyodemografik veriler arasında ise anlamlı ilişki saptanmadı. Hasta sayımızın kısıtlı olması ve sadece kadın popülasyonu içermesi özellikle sosyo-demografik veriler ve yaşam kalitesi arasındaki ilişkinin değerlendirilmesinde, çalışmamızın limitasyonunu oluşturmaktadır. Fibromiyalji alanında her iki cinsiyeti de içeren, daha geniş popülasyonlu çalışmalara intiyaç vardır.

\section{Kaynaklar}

1. Bellato $E$, Marini $E$, Castoldi $F$, et al. Fibromyalgia syndrome: etiology, pathogenesis, diagnosis, and treatment. Pain Research and Treatment 2012;2012:426130.

2. Clauw DJ. Fibromyalgia: an overview. The American Journal of Medicine 2009;122(Suppl 12):3-13.

3. Pagano T, Matsutani LA, Ferreira EAG, Marques AP, Pereira CAdB. Assessment of anxiety and quality of life in fibromyalgia patients. Sao Paulo Medical Journal 2004;122:252-8.

4. Price DD, Staud R. Neurobiology of fibromyalgia syndrome. The Journal of Rheumatology Supplement 2005;75:22-8.

5. Epstein SA, Kay G, Clauw D, et al. Psychiatric disorders in patients with fibromyalgia. A multicenter investigation. Psychosomatics 1999;40:57-63. 
6. Abeles AM, Pillinger MH, Solitar BM, Abeles M. Narrative review: the pathophysiology of fibromyalgia. Annals of Internal Medicine 2007;146:726-34

7. McBeth J, Silman AJ. The role of psychiatric disorders in fibromyalgia. Current Rheumatology Reports 2001;3:157-64.

8. The World Health Organization Quality of Life assessment (WHOQOL): position paper from the World Health Organization. Soc Sci Med 1995;41:1403-9.

9. Wolfe F, Aarflot $T$, Bruusgaard D, et al. Fibromyalgia and disability. Report of the Moss International Working Group on medico-legal aspects of chronic widespread musculoskeletal pain complaints and fibromyalgia. Scandinavian Journal of Rheumatology 1995;24:112-8.

10. Henriksson C, Burckhardt C. Impact of fibromyalgia on everyday life: a study of women in the USA and Sweden. Disability and Rehabilitation 1996;18:241-8.

11. Campos R, Vázquez M. Health-related quality of life in women with fibromyalgia: clinical and psychological factors associated. Clinical Rheumatology 2012;31:347-55.

12. Homann D, Stefanello JM, Goes SM, Breda CA, Paiva Edos S, Leite $\mathrm{N}$. Stress perception and depressive symptoms: functionality and impact on the quality of life of women with fibromyalgia. Revista Brasileira de Reumatologia 2012;52:319-30.

13. Leith S, Wheatley RG, Jackson IJ, Madej TH, Hunter D. Extradural infusion analgesia for postoperative pain relief. British Journal of Anaesthesia 1994;73:552-8.

14. Beck AT, Ward $\mathrm{CH}$, Mendelson M, Mock J, Erbaugh J. An inventory for measuring depression. Archives of General Psychiatry 1961:4:561-71.

15. Kapci EG, Uslu R, Turkcapar H, Karaoglan A. Beck Depression Inventory II: evaluation of the psychometric properties and cutoff points in a Turkish adult population. Depression and Anxiety 2008;25:104-10

16. Sarmer S, Ergin S, Yavuzer G. The validity and reliability of the Turkish version of the Fibromyalgia Impact Questionnaire. Rheumatology International 2000;20:9-12.

17. Burckhardt CS, Clark SR, Bennett RM. The fibromyalgia impact questionnaire: development and validation. The Journal of Rheumatology 1991;18:728-33.

18. Tuzun EH, Albayrak G, Eker L, Sozay S, Daskapan A. A comparison study of quality of life in women with fibromyalgia and myofascial pain syndrome. Disability and Rehabilitation 2004;26:198-202.

19. Wolfe F, Ross K, Anderson J, Russell IJ, Hebert L. The prevalence and characteristics of fibromyalgia in the general population. Arthritis and Rheumatism 1995;38:19-28.

20. Consoli G, Marazziti D, Ciapparelli A, et al. The impact of mood, anxiety, and sleep disorders on fibromyalgia. Comprehensive Psychiatry 2012;53:962-7.

21. Ubago Linares Mdel C, Ruiz-Perez I, Bermejo Perez MJ, Olry de Labry-Lima A, Hernandez-Torres E, Plazaola-Castano J. Analysis of the impact of fibromyalgia on quality of life: associated factors. Clinical Rheumatology 2008;27:613-9.
22. Spaeth M, Briley M. Fibromyalgia: a complex syndrome requiring a multidisciplinary approach. Human Psychopharmacology 2009; 24(Suppl 1):3-10.

23. Ablin J, Neumann L, Buskila D. Pathogenesis of fibromyalgia - a review. Joint, Bone, Spine : Revue du Rhumatisme 2008;75: 2739

24. Spaeth M, Rizzi M, Sarzi-Puttini P. Fibromyalgia and sleep. Best Practice \& Research Clinical Rheumatology 2011;25:227-39.

25. Fietta P, Manganelli P. Fibromyalgia and psychiatric disorders. Acta Bio-medica : Atenei Parmensis 2007;78:88-95.

26. Martinez JE, Ferraz MB, Fontana AM, Atra E. Psychological aspects of Brazilian women with fibromyalgia. Journal of Psychosomatic Research 1995;39:167-74.

27. Aguglia A, Salvi V, Maina G, Rossetto I, Aguglia E. Fibromyalgia syndrome and depressive symptoms: comorbidity and clinical correlates. Journal of Affective Disorders 2011;128:262-6.

28. Thieme K, Turk DC, Flor H. Comorbid depression and anxiety in fibromyalgia syndrome: relationship to somatic and psychosocial variables. Psychosomatic Medicine 2004;66:837-44.

29. Celiker R, Borman P, Oktem F, Gokce-Kutsal Y, Basgoze O. Psychological disturbance in fibromyalgia: relation to pain severity. Clinical Rheumatology 1997;16:179-84.

30. Rijavec N, Grubic VN. Depression and pain: often together but still a clinical challenge: a review. Psychiatria Danubina 2012;24: 346-52.

31. Anch AM, Lue FA, MacLean AW, Moldofsky H. Sleep physiology and psychological aspects of the fibrositis (fibromyalgia) syndrome. Canadian Journal of Psychology 1991;45:179-84.

32. Wolfe F, Clauw DJ, Fitzcharles MA, et al. The American College of Rheumatology preliminary diagnostic criteria for fibromyalgia and measurement of symptom severity. Arthritis Care \& Research 2010;62:600-10.

33. Wagner JS, Dibonaventura MD, Chandran AB, Cappelleri JC. The association of sleep difficulties with health-related quality of life among patients with fibromyalgia. BMC Musculoskeletal Disorders 2012;13:199.

34. Martins MR, Polvero LO, Rocha CE, Foss MH, Santos Junior RD. Using questionnaires to assess the quality of life and multidimensionality of fibromyalgia patients. Revista Brasileira de Reumatologia 2012;52:21-6.

35. Assumpção A, Pagano T, Matsutani LA, Ferreira EAG, Pereira $C A B$, Marques AP. Quality of life and discriminating power of two questionnaires in fibromyalgia patients: fibromyalgia Impact Questionnaire and Medical Outcomes Study 36-Item Short-Form Health Survey. Revista Brasileira de Fisioterapia 2010;14:284-9.

36. Van Abbema R, Van Wilgen CP, Van Der Schans CP, Van Ittersum $\mathrm{MW}$. Patients with more severe symptoms benefit the most from an intensive multimodal programme in patients with fibromyalgia. Disability and Rehabilitation 2011;33:743-50. 